Научная статья

УДК 303; 323

DOI 10.25205/2541-7517-2021-19-3-68-86

\title{
Современные подходы
}

\section{к исследованию этнической идентичности}

\section{Ольга Алексеевна Персидская ${ }^{1}$ \\ Федор Сергеевич Фомкин ${ }^{2}$}

${ }^{1,2}$ Институт философии и права

Сибирского отделения Российской академии наук

Новосибирск, Россия

${ }^{1}$ olga_alekseevna@mail.ru

2 iamfomkin@mail.ru

\section{Аннотация}

На основе анализа современных теоретических и практических исследований в социальной философии, социологии и социальной психологии рассмотрены тенденции, связанные с интерпретацией феномена этнической идентичности. Описана множественная трактовка этого феномена, позволяющая изучать его разные формы и степени выраженности. Сетевые социальные медиа, полиэтническая городская среда и процессы в несистемной политике рассмотрены как социокультурные факторы, оказывающие влияние на трансформацию рассматриваемого феномена. Сделан вывод, что процесс этнической идентификации нельзя более отождествлять со шкалой, направленной от нулевого состояния (идентичность не сформирована) к положительному полюсу (идентичность сформирована и выражена). Вместо этой одномерной трактовки предложена метафора пространства, включающего разные формы и степени выраженности этнической идентичности.

Ключевые слова

этническая идентичность, юношество, факторы этнической идентичности, город, современные масс-медиа, политизация этнической идентичности

Благодарности

Исследование выполнено при финансовой поддержке РФФИ и Правительства Новосибирской области в рамках научного проекта № 20-411-543001 «Влияние этнической идентичности на представления о межэтнической интеграции у юношества в городском сообществе»

Для циттирования

Персидская О. А., Фомкин Ф. С. Современные подходы к исследованию этнической идентичности // Сибирский философский журнал. 2021. Т. 19, № 3. С. 68-86. DOI 10.25205/2541-7517-2021$19-3-68-86$

( П Персидская О. А., Фомкин Ф. С., 2021 


\title{
Contemporary Approaches to the Study of Ethnic Identity
}

\author{
Olga A. Persidskaya ${ }^{1}$, Fedor S. Fomkin ${ }^{2}$
}

Institute of Philosophy and Law

of the Siberian Branch of the Russian Academy of Sciences

Novosibirsk, Russian Federation

1 olga_alekseevna@mail.ru

2 iamfomkin@mail.ru

Abstract

Based on the analysis of contemporary theoretical and practical research in the fields of social philosophy, sociology and social psychology, the author considers trends related to the interpretation of the phenomenon of ethnic identity. A multiple interpretation of this phenomenon is described, which allows us to study its different forms and degrees of manifestation. Network social media, multi-ethnic urban environment and processes in non-systemic politics are considered as socio-cultural factors that influence the transformation of the phenomenon under consideration. It is concluded that the process of ethnic identification cannot be further unambiguously identified with a scale directed from the zero state (identity is not formed) to the positive pole (identity is formed and expressed). Instead of this onedimensional interpretation, a metaphor of space, which includes different forms and degrees of expression of ethnic identity, is proposed.

Keywords

ethnic identity, youth, factors of ethnic identity, city, modern mass media, politicization of ethnic identity

Acknowledgements

The research was funded by RFBR and Novosibirsk region, project no. 20-411-543001 "The impact of ethnic identity on the perception of interethnic integration among young people in the urban community"

For citation

Persidskaya O. A., Fomkin F. S. Contemporary Approaches to the Study of Ethnic Identity. Siberian Journal of Philosophy, 2021, vol. 19, no. 3, pp. 68-86. (in Russ.) DOI 10.25205/2541-7517-2021-19-368-86

Этническая идентичность является предметом значительного числа теоретических и эмпирических исследований ряда социально-гуманитарных наук. Как было показано в [Персидская, 2021], в части этих исследований этническая идентичность предстает в качестве одномерного параметра, являющегося компонентом «идентификационной матрицы» индивида. Это означает, что с точки зрения исследователей человек способен дать четкий и однозначный ответ на вопрос о том, какова его этническая принадлежность, и этот ответ становится основой для построения дальнейших суждений об обществе. Эти суждения часто имеют форму обобщений вида «большинство опрошенных русских считают, что...» 
и сводят всех людей, отметивших в анкете исследования себя как русского, в гомогенную группу с некоторыми общими характеристиками. На наш взгляд, такая трактовка этнической идентичности интерпретирует ее несколько одномерно.

Отдельный класс исследований представляют работы, сосредоточенные на выявлении влияния, которое оказывает этническая идентичность на разные области социальной жизни личности. Например, в части работ по теме этнической идентичности подростков показано, что, чем глубже личность осознает свою идентичность, тем сильнее она ориентирована на позитивное восприятие иноэтничного окружения, толерантность, сокращение социальной дистанции между представителями разных этнических групп [см., напр., Белинская, Стефаненко, 2000 , с. 205]. Другими исследователями доказано, что у подростков с выраженной этнической идентичностью и положительным отношением к своей этнической группе зафиксированы такие положительные эффекты, как более высокая самооценка и меньшая склонность к депрессиям [Umaña -Taylor, Updegraf, 2007], хорошая академическая успеваемость [Adelabu, 2008; Rogers et al., 2015], снижение желания употреблять алкоголь и никотин [Guilamo-Ramos, 2009; Yu \& Stifman, 2007]. Не отрицая значимости упомянутых и подобных исследований, позволим себе заметить, что в них этническая идентичность рассматривается как нечто, что может иметь ряд форм, располагающихся в континууме от невыраженной этнической идентичности до полностью выраженной (обретенной). Важно, что положительные социальные эффекты связываются в основном с формой, имеющей наибольшую степень выраженности или наибольшую полноту обретения этнической идентичности. При этом другие позиции, которые может иметь этническая идентичность у разных людей (неотрефлексированная, множественная, скрытая и др.), остаются недостаточно изученными. Эта ситуация имеет значительное влияние не только на мыслительные паттерны в академической среде, но и воздействует на связанные с этнической проблематикой цели образовательных программ, правительственные стратегии, мероприятия, проводимые некоммерческими организациями.

На наш взгляд, этническая идентичность является сложным и многогранным феноменом, постоянно изменяющимся под действием факторов среды, в которой находятся ее носители. Подобную точку зрения разделяют значительное число исследователей как за рубежом, так и в нашей стране, поэтому анализ и обобщение современных подходов, связанных с изучением феномена этнической идентичности, кажется нам значимой целью. Таким образом, задачами статьи являются, во-первых, расширение социально-философской интерпретации феномена «этническая идентичность» с опорой на современные отечественные 
и зарубежные исследования в этой области, во-вторых, описание факторов, оказывающих влияние на формирование этнической идентичности в полиэтническом городском сообществе, в-третьих, выявление актуальных направлений для исследований в поле, связанном с содержанием феномена этнической идентичности.

\section{Этническая идентичность: к многомерной трактовке феномена}

Уйти от одномерной трактовки этнической идентичности и раскрыть ее сущность в единстве составляющих частей помогают идеи, сформулированные в области науки, находящейся на пересечении социологии и социальной психологии. Значительная часть этих идей развивает подходы неопсихоаналитической социально-психологической концепции эго-идентичности Эрика Эриксона [Erikson, 1968]. К их числу можно отнести теорию социальной идентичности А. Тешфела и Д. Тернера (Social Identity Theory, SIT) [Tajfel, Turner, 1979] и ролевую концепцию этнической идентичности [Бергер, 1996]. В рамках подобных подходов этническая идентичность лишена онтологических оснований, то есть речи о ее объективной (например, биологической) заданности не идет, а исследуются социальные механизмы, делающие этническую идентичность объективной психологической реальностью [Phinney, 1989; Zagefka, 2009; Abizadeh, 2001; Verkuyten, 2005].

Этническая идентичность раскрывается как многомерная конструкция за счет того, что в ней разделяются структурная и процессуальная составляющие. В рамках структурной составляющей отдельно представлены когнитивный, аффективный и поведенческий компоненты, которые выделяют в соответствии со структурой, принятой для описания социальной установки. В рамках когнитивного компонента изучают идентификацию личностью себя как члена этнической группы и наличие некоторого объема знаний о ней: языке, традициях, обычаях, истории, культуре, ценностях и пр. Аффективный компонент связывают с чувствами, которые ассоциированы у личности с осознанием собственной этнической принадлежности, актуальностью этнической идентичности и ощущением общности со своей этнической группой. Поведенческий компонент, наиболее спорный с теоретической точки зрения и сложно фиксируемый в эмпирических исследованиях, отражается в том, как индивид организует свою бытовую и общественную жизнь с учетом осознания себя носителем определенной этнической идентичности [Barrett, 1996; Umaña-Taylor et al., 2014]. 
Важными показателями, помогающими операционализировать структурные компоненты этнической идентичности для эмпирических социологических и социально-психологических исследований, являются валентность и определенность (или выраженность) этнической идентичности. Так, валентность фиксирует эмоциональность этнической идентичности, то есть то, как - позитивно или негативно - у личности окрашен аффективный компонент ее этнической идентичности. Определенность задается степенью ясности осознания личностью себя как представителя этнической группы, а также характеризуется широтой набора знаний о ней [Татарко, Лебедева, 2010] (все это имеет отношение в первую очередь к когнитивному компоненту этнической идентичности).

Процессуальная составляющая позволяет соотнести этапы взросления личности и стадии ее этнической идентификации. Подробно она была исследована и описана американским этнологом Дж. Финни, которая, в свою очередь, опиралась на теорию идентичности, предложенную Эриксоном и позднее развитую Дж. Марсиа [Marcia, 1993]. Финни сосредотачивается на подростковом возрасте, признавая за этим периодом наиболее значимую роль в становлении и формировании идентичности в силу повышающейся способности к рефлексии, обретения личностью более широких социальных связей (выходящих за границы собственной этнической группы), бо́льшего внимания к общественной жизни и внешнему виду.

Процесс формирования этнической идентичности по Дж. Финни, состоит из трёх стадий. Первая - стадия неисследованной (непроверенной) этнической идентичности. Она характерна для доподросткового возраста, когда дети принимают свою идентичность как данность, перенимая ее от родителей без самостоятельного рефлексирования и конструирования. Ранний опыт детей считается решающим для развития их этнической идентичности. Вторая стадия связана с самостоятельным поиском этнической идентичности и носит название «мораторий». С началом подросткового возраста общепринятые взгляды на этническую идентичность ставятся под сомнение. Идет процесс накопления значительного опыта, который создает базу для самостоятельного глубокого осознания этнической принадлежности, в том числе эпизодов, связанных с дискриминацией. Подобная рефлексия включает в себя интерес к получению знаний о культуре, присущей предполагаемой идентичности, обсуждение с другими людьми своей этнической принадлежности, чтение книг по этой теме и размышления о текущих и будущих последствиях принятия своей этнической идентичности. Третья стадия - достижение этнической идентичности - включает в себя безопасное, уверенное и стабильное чувство собственного достоинства, наличие реалистичной оценки своей группы (групп). По сути, на этой стадии индивид 
полностью усваивает свою этническую принадлежность. Дж. Финни признает, что в течение жизни человек может пересмотреть содержание собственной этнической идентичности в зависимости от опыта, полученного с течением времени. Как правило, третья стадия завершается с окончанием подросткового возраста и переходом к взрослости [Phinney, 1989, 1990; Phinney, Ong, 2007].

\section{Социокультурные факторы трансформации этнической идентичности}

Для того чтобы понять специфику трансформаций, происходящих с этнической идентичностью в современном мире, необходимо выйти за рамки моделей, предлагаемых социальной психологией. Необходимо учитывать общий социальный и культурный контекст ее бытования, а также отдельные политические и идеологические факторы, которые оказывают влияние на социальную жизнь в целом и вплетенные в нее этнические феномены в частности. Описание таких трансформаций методологически тяготеет к социокультурному подходу, в рамках которого всестороннее изучение этносоциальных процессов опирается на широкий социокультурный контекст, формируемый разными факторами [Попков и др., 2020]. Такого рода описание сосредоточено на выявлении особенностей, имеющих отношение в первую очередь к этническим феноменам: «Эти исследования предполагают как рассмотрение различных аспектов проявлений этничности в современных социальных и политических процессах, так и изучение социальной структуры общества, факторов его динамики» [Белокопыт, 2004, c. 3].

Не претендуя на всестороннее описание темы, отметим лишь несколько факторов, которые, на наш взгляд, оказывают наиболее сильное влияние на трансформацию этнической идентичности, и сделаем выводы о том, как именно она может меняться под их воздействием. Кратко общее содержание и смысл процессов, происходящих в том числе с этнической идентичностью, описала еще М. Мид в своей концепции префигуративной культуры. В рамках такой культуры меняется сам процесс воспроизводства этнической идентичности: она более не передается «через обучение родному языку, благодаря усвоению социальных отношений и ценностей, ... которые передаются в процессе воспитания новых поколений в нормах, традициях и нравах» [Ушаков, 2009, с. 101]. По М. Мид, подросток выстраивает систему своих социальных идентичностей с гораздо более значительной опорой на собственные убеждения, чем это было в предыдущих поколениях: «Еще совсем недавно старшие могли говорить: “Послушай, я был молодым, а ты никогда не был старым”. Но сегодня молодые могут им от- 
ветить: “Ты никогда не был молодым в мире, где молод я, и никогда не будешь” [Мид, 1988, с. 360].

Тем не менее, проблема идентичности не теряет для личности своей актуальности. В условиях современных социокультурных трансформаций она становится даже более острой. Ч. Тилли фиксирует актуализацию явлений, связанных с идентификацией: «Глобализация, быстрое развитие многокультурных городских обществ, растущее влияние многонациональных корпораций..., а также сопутствующая этому незащищенность на рынке труда, диаспоры и крупномасштабные перемещения и перемешивания людей, туризм и путешествия, интернет и разрушающееся чувство пространства и времени, - все эти и многие другие факторы заставляют людей задавать вопросы об идентичности» [Tilley, 2006, p. 8]. Этническая идентичность не утрачивает своей значимости, но ее содержание подвергается значительным трансформациям.

Сетевые социальные медиа. Совершенствование и растущая популярность платформ интернета способствуют перемещению значительной части коммуникации в виртуальное пространство. Процесс настолько глобален, что заставляет исследователей говорить о качественно новом этапе эволюции Homo Sapiens Homo Cyberus [Плешаков, 2009] или Homo Virtualis [Афанасьева, 2010], и о формировании жизненно освоенной виртуальной социальной реальности.

Если ранее этническая идентичность была тесно связана с такими социальными институтами, как семья, ближайшее окружение и система образования, то в настоящее время исследователи фиксируют глубинные изменения, связанные с нивелированием роли этих институтов и переориентацией на медиа как важный фактор идентификации. Важно подчеркнуть, что происходит также переход этноформирующей коммуникации от старых медиа (телевидения, радио, газет и пр.) к новым, в частности, сетевым социальные медиа. Изучение и описание этого перехода иногда называют «ключевой интеллектуальной интуицией этносоциологии XXI в.» [Глухов, 2015].

К сетевым социальным медиа относят массовую интернет-коммуникацию на базе сетей и виртуальных сообществ. Если в старых медиа коммуникаторами выступали в основном элиты (политические, интеллектуальные или культурные), а дискурс имел публичный характер и отличался использованием высокого жанра и небытовой стилистики, что способствовало сохранению статусной дистанции между коммуникаторами и аудиторией, то в новых медиа ситуация совершенно иная. Здесь коммуникаторами могут стать как активные пользователи социальных сетей, так и активисты-модераторы, которые, как правило, не являются представителями этнических элит и официальными лицами, но имеют статус лидеров мнений. Трансформируются и коммуникативные жанры: блоги, ка- 
налы, сообщества, форумы в социальных сетях имеют выраженный социальносетевой характер. Меняется не только способ доставки посланий, но и их содержание. Дискурс становится межперсональным и полупубличным, за счет чего дистанция между коммуникатором и аудиторией существенно уменьшается или исчезает вовсе. Все это оказывает влияние на тип идентичности, к конструированию которой этот дискурс имеет отношение. Е. П. Белинская и Т. Г. Стефаненко выделяют следующие особенности этнической идентичности у молодежи, складывающиеся под сильным влиянием виртуальной среды: анонимность; возможность «игры» с ролями и построения множественного «Я»; необходимость самопрезентации [Белинская, Стефаненко, 2000, с. 102]. Все это позволяет утверждать, что виртуальная реальность предлагает человеку максимум возможностей для конструирования собственной этнической идентичности.

М. Прайс нашел для описания такой ситуации очень удачную метафору, сравнив масс-медиа с рынком лояльностей, продавцы на котором - транснациональные корпорации, государства и иные социальные институты - предлагают покупателям разные «продукты» идентичности, требуя в качестве оплаты определенного уровня лояльности и мобилизации [Прайс, 2000]. В современном медиа-процессе виртуальные этнические сообщества также предстают как публичные арены, где пользователям предлагаются конкурирующие продукты идентичности [Казарян, 2018]. Таким образом, новая коммуникативная инфраструктура социальных платформ трансформирует пространство общения, идентичность, язык дискурса и его функции, превращая виртуальные этнокомьюнити в квазиинститут накопления социального капитала [Глухов, 2015]. Эта виртуальная среда выполняет ряд функций, связанных как с организацией экономических, культурных, религиозных и досуговых социальных практик, так и с воспроизводством этнической идентичности. Особенно ярко данные тенденции (уход от традиционных институтов и ориентация на новые медиа) выражены у молодежи, что подтверждают многочисленные исследования [см., например, Дружба, Каирова, Кошман, 2000; Матвеева, 2016].

Урбанизированная среда. Город включен в область социально-философского осмысления как сложносоставной объект. Его пространство, очерченное географическими границами (впрочем, границы чаще понимаются как условные из-за подвижности и изменчивости наполняющих их структур), исследуется в связке с пространством городских смыслов, сетей, идентичностей. Эту двойственность В. С. Вахштайн фиксирует так: «Город - топологически множественный объект, существующий одновременно в сетевом и евклидовом пространстве (более корректно, но менее грамотно: “имеющий две формы пространственности”)» [Вахштайн, 2014, с. 27]. Таким образом, не только отдельные идентичности горожан, 
но идентичность города как отдельного социокультурного объекта является сложносоставным и подвижным феноменом.

Исследователи фиксируют, что попытки унифицировать идентичность города или горожан в некотором наборе социологических портретов чаще всего терпят неудачу из-за чрезвычайной сложности объектов описания: «Предпосылки любого исследования границ идентичности и пространственных границ заставляют отказаться не только от попыток создания типовой модели жителя того или иного города (москвича, петербуржца, парижанина), что лишено какой-либо актуальности в современных условиях, но и от принятия городской идентичности как целостного культурного типа, охарактеризованного определенными маркерами» [Николаева, Троицкая, 2020, с. 25].

При этом осознание этнической принадлежности во множестве ее измерений и состояний также входит в идентичность горожан как ее составная часть. В сумме мы имеем сложный и подвижный этнический портрет города. Значимым фактором, оказывающим влияние на этническую идентичность горожанина и города, являются миграционные процессы. Говоря о городе как социокультурном пространстве, недостаточно ограничиться заключением, что миграция лишь изменяет распределение долей разноэтнического населения; важно, что она вызывает качественные трансформации городского сообщества на уровне структурно-функциональной организации и социально-антропологических характеристик. Согласимся с Ю. В. Попковым и Е. А. Тюгашевым: «Город осуществляет отбор мигрантов, адаптивных к его условиям и вписывающихся в городское сообщество», тем самым проявляя себя как интегрированное целое, а «изменение этносоциального состава населения влечет за собой реорганизацию межэтнических отношений в городском сообществе и его социокультурную трансформацию, которая не всегда происходит гладко и безболезненно» [Попков, Тюгашев, 2017, c. 9].

Политизащия этнических и расовых проблем. Под политизацией этничности чаще всего понимается участие представителей этнических групп в системной политике, направленное на борьбу с этническим и социальным неравенством, а также на те или иные социальные и политические преобразования [Weber et al., 2016]. Однако под влиянием политических событий, произошедших в последние годы, растущей популярности общественных движений, таких как Black Lives Matter, все больше представителей этнических групп вовлекаются в сферу несистемной политики. Под такой политикой подразумеваются демонстрации, забастовки, бунты и другие виды социального активизма. Это оказывает влияние на смещение исследовательского фокуса в изучении политизации этничности. 
Для рассмотрения данных процессов многие исследователи начинают применять теорию критического сознания [Heberle et al., 2020].

Теория критического сознания в приложении к проблематике политизации этничности объединяет идеи, основанные на концепции консайентизации П. Фрейре. Консайентизация представляет собой процесс, в ходе которого люди, испытывающие трудности с социальной интеграцией, принимают меры для преодоления социального неравенства [Freire, 2000]. Механизм консайентизации проходит путем критического размышления о причинах социального неравенства и критического действия (участие в акциях, направленных на социальные преобразования, как правило, заключающиеся в проявлениях несистемной политики: активизме, бунтах и забастовках). Хотя критическое размышление и критическое действие являются наиболее известными аспектами критического сознания, также следует сказать о его третьем компоненте, описанном в современных концептуализациях. Речь идет о политической эффективности, выдвигающей на первый план убеждения индивида касательно его способности влиять на социальные преобразования [Jemal, 2017; Watts et al., 2011]. Фрейре и другие современные исследователи критического сознания [Watts, Flanagan, 2007] рассматривают взаимосвязь между критическим размышлением, политической эффективностью и критическим действием. Иными словами, участие в политических действиях может побуждать людей к дальнейшим размышлениям о неравенстве; эти размышления могут стать основой мотивации к достижению равенства, а затем приводить и к гражданским действиям [Diemer et al., 2015].

Обобщая рассмотрение современных интенций в социально-гуманитарном знании, связанных с расширением интерпретации феномена этнической идентичности, заключим, что его многомерная трактовка, постепенно принимаемая социологией и социальной философией, позволяет изучать разные формы этнической идентичности и степени ее выраженности. В связи с этим предположим, что, по-видимому, нормой в современном мире могут стать разные по степени наполнения когнитивного, аффективного и поведенческого компонентов формы этнической идентичности, а процесс этнической идентификации не всегда может быть в полной мере завершен к окончанию подросткового возраста. Все это говорит о том, что процесс этнической идентификации нельзя и дальше однозначно отождествлять со шкалой, направленной от нулевого состояния (идентичность не сформирована) к положительному полюсу (идентичность сформирована и выражена): здесь, скорее, допустима метафора пространства, включающего разные формы и степени выраженности этнической идентичности. 
Так как большинство исследователей сходятся в убеждении, что формирование этнической идентичности завершается в юношеском возрасте, отметим, что именно поэтому особенно актуально исследование параметров формирования этнической идентичности у подростков, впечатления которых свежи, а воспоминания о значимых событиях отчетливы. Исследователи зафиксировали тенденции, приводящие к снижению выраженности этнической идентичности у этой возрастной группы, трансформации механизмов ее воспроизведения и изменению содержания.

К социокультурным факторам, оказывающим влияние на трансформацию этнической идентичности, были отнесены сетевые социальные медиа, урбанизированная среда и политизация этнической идентичности. Именно сетевые социальные медиа сегодня являются пространством, где происходит трансформация традиционных форм идентификации, а также вместилищем основного объема социальных отношений, в том числе межэтнических. При этом образ этнического сообщества виртуализируется, отрываясь от таких материальных феноменов, как «родная земля», «род», «семья» и пр., к которым он был традиционно привязан. Это приводит к тому, что виртуальная идентичность совмещается с той, что создается вне сети, и разобраться в том, чем она обоснована в большей степени, становится достаточно сложно. Одновременно фиксируется смена оснований, фундирующих этническую идентичность в медиасреде: переход от традиционных социальных институтов к медиа-институтам и от старых медиа к новым.

Академический дискурс, касающийся влияния современного полиэтнического города на становление этнической идентичности, в наиболее острой форме ставит вопросы о миграции как факторе, изменяющем социокультурное пространство города и его восприятие горожанами. Полифония различающихся этнических идентичностей в неоднородной среде города в условиях миграционного прироста остро ставит вопрос не только об адаптации мигрантов к принимающему сообществу, но и последнего - к мигрантам. Кроме того, становится очевидным, что об этнических идентичностях горожан следует рассуждать, с одной стороны, с точки зрения стабильности и изменчивости, a, с другой, рассматривать их как сложносоставной феномен.

Зафиксирован поворот в исследовании политизации этничности: если раньше она рассматривалась в основном с точки зрения влияния этнического фактора на процессы в системной политике, то сейчас актуальным становится рассмотрение процессов в несистемной политике через призму критического сознания акторов, актуально или потенциально в ней участвующих. Немногие исследователи рассматривают все три компонента критического сознания (критическое размышление, критическое действие и политическая эффективность) 
одновременно; нам удалось найти такое сочетание лишь у [Diemer, Rapa, 2016]. Дальнейшее исследование в рамках данной концепции представляется чрезвычайно важным.

Если говорить о направлениях исследований, которые могут быть актуальны в поле, связанном с содержанием феномена этнической идентичности, то, на наш взгляд, к ним относится как выявление статуса этнической идентичности (к какой именно этнической группе / группам себя причисляет человек), так и выяснение неочевидных характеристик ее состояния, параметров выраженности, истории становления. Такой подход созвучен также тенденциям развития современного мира, отказывающегося от одномерных трактовок разных идентичностей в пользу сложных конструктов. Кроме того, актуальным видится переосмысление структуры и содержания указанного феномена с учетом трансформаций, накладываемых условиями существования современных социумов. Отметим, что попытки эмпирического исследования содержания этнической идентичности с выявлением связей и зависимостей между ее компонентами весьма ограничены. Дополнительного изучения также требует взаимосвязь этнической идентичности с другими феноменами, например, со стратегиями межэтнической интеграции.

\section{Список литературы}

Афанасьева В. В. Ноmo Virtualis: психологические характеристики // Изв. Сарат. ун-та. Новая серия. Сер.: Философия. Психология. Педагогика. 2010. Т. 10, № 2. C. 59-64.

Белинская Е. П., Стефаненко Т. Г. Этническая социализация подростка. М.; Воронеж: НПО «МОДЭК», 2000.

Белокопыт А. Н. Этносоциальные процессы в условиях социальной трансформации: на примере Ставропольского края: Автореф. дис. ... канд. социол. наук. М., 2004.

Бергер П. Приглашение в социологию: гуманистическая перспектива. М.: Аспект-пресс, 1996.

Вахштайн В. С. Пересборка города: между языком и пространством // Социология власти. 2014. № 2. С. 9-38.

Глухов А. П. Смена локуса этнического дискурса: социальные сети как «машины воспроизводства» этничности // Science Time. 2015. № 10 (22). С. 68-73.

Дружба О. В., Каирова И. А., Кошман Н. В. Социальные сети как пространство интернет-социализации молодежи // KANT. 2020. № 1 (34). С. 143-151. 
Казарян А. Г. Коммуникативный фактор в этногенезе // Аспирантский вестник Поволжья. 2018. № 7-8. С. 25-29.

Матвеева Е. В. Соцсети как средство формирования этнической идентичности молодежи в досуге // Байкальские встречи: этничность в контексте социально-культурного и экономического развития региона: Материалы Междунар. науч.-практ. конф. Улан-Удэ, 2016. С. 78-83.

Мид М. Культура и мир детства: Избр. произв. М.: Наука, 1988.

Николаева Ж. В., Троицкая А. А. Дискурс об идентичности как способ осмысления городского пространства // Журнал фронтирных исследований. 2020. T. 5, № 1. C. 11-28. DOI 10.24411/2500-0225-2020-10001

Персидская О. А. Влияние этнической идентичности на представления о межэтнической интеграции: к постановке проблемы // Respublica Literaria. 2020. T. 2, № 1. C. 95-103. DOI 10.47850/RL.2021.2.1.95-103

Плешаков В. А. Киберсоциализация как инновационный социально-педагогический феномен // Преподаватель XXI век. 2009. № 3-1. С. 32-39.

Попков Ю. В., Костюк В. Г., Персидская О. А. Институционализация Новосибирской научной этносоциологической школы: идеи, подходы, формы деятельности // Respublica Literaria. 2020. T. 1, № 1. C. 103-111. DOI 10.47850/ RL.2020.1.1.103-117

Попков Ю. В., Тюгашев Е. А. Феномен города как межэтнического сообщества // Всеросс. экон. журн. ЭКО. 2017. Т. 47, № 10. С. 7-19. DOI 10.30680/ ЕСО0131-7652-2017-10-7-19

Прайс М. Телевидение, телекоммуникации и переходный период: право, общество и национальная идентичность. М.: МГУ, 2000.

Татарко А. Н., Лебедева Н. М. Психология межэтнических отношений. Этническая идентичность и стратегии межкультурного взаимодействия. Lambert Academic Publishing, 2010.

Ушаков Д. В. Роль семьи в воспроизводстве этничности народов Республики Алтай // Социол. исслед. 2009. № 3. С. 101-108.

Abizadeh A. Ethnicity, Race, and a Possible Humanity. World Order, 2001, no. 33, pp. 23-34.

Adelabu D. H. Future Time Perspective, Hope, and Ethnic Identity among African American Adolescents. Urban Education, 2008, no. 43, pp. 347-360. DOI 10.1177/ 0042085907311806

Barrett M. English Children's Acquisition of a European Identity. In: Breakwell G., Lyons E. (eds.). Changing European Identities: Social-Psychological Analyses of Social Change. Oxford, Butterworth-Heinemann, 1996, pp. 145-172. 
Diemer M. A., Rapa L. J. Unraveling the Complexity of Critical Consciousness, Political Efficacy, and Political Action among Marginalized Adolescents. Child Development, 2016, no. 87, pp. 221-238. DOI 10.1111/cdev.12446

Diemer M. A., McWhirter E. H., Ozer E. J., Rapa L. J. Advances in the Conceptualization and Measurement of Critical Consciousness. The Urban Review, 2015, no. 47, pp. 809-823. DOI 10.1007/s11256-015-0336-7

Erikson E. H. Identity Youth and Crisis. New York, London, WW Norton \& Company, 1968.

Freire P. Pedagogy of the Oppressed. New York, Continuum, 2005.

Guilamo-Ramos V. Maternal Infuence on Adolescent Selfesteem, Ethnic Pride and Intentions to Engage in Risk Behavior in Latino Youth. Prevention Science, 2009, no. 10, pp. 366-375. DOI 10.1007/s11121-009-0138-9

Heberle A. E., Rapa L. J., Farago F. Critical Consciousness in Children and Adolescents: A Systematic Review, Critical Assessment, and Recommendations for Future Research. Psychological Bulletin, 2020, no. 146, pp. 525-551. DOI 10.1037/ bul0000230

Jemal A. Critical Consciousness: A Critique and Critical Analysis of the Literature. The Urban Review, 2017, no. 49, pp. 602-626. DOI 10.1007/s11256-017-0411-3

Marcia J. E. The Ego Identity Status Approach to Ego Identity. In: Ego Identity. New York, Springer, 1993.

Phinney J. S., Ong A. D. Conceptualization and Measurement of Ethnic Identity: Current Status and Future Directions. Journal of Counseling Psychology, 2007, no. 54, pp. 271-281. DOI 10.1037/0022-0167.54.3.271

Phinney J. S. Ethnic Identity in Adolescents and Adults: Review of Research. Psychological Bulletin, 1997, no. 108, pp. 499-514. DOI 10.1037/0033-2909.108.3.499

Phinney J. S. Stages of Ethnic Identity Development in Minority Group Adolescents. The Journal of Early Adolescence, 1989, no. 9, pp. 34-49. DOI 10.1177/02724316 89091004

Rogers L. O., Scott M. A., Way N. Racial and Gender Identity among Black Adolescent Males: An Intersectionality Perspective. Child Development, 2015, no. 86, pp. 407-424. DOI 10.1111/ cdev.12303

Tajfel H., Turner J. C. An Integrative Theory of Intergroup Conflict. In: Austin W. G., Worchel S. (eds.) The social psychology of intergroup relations. Monterey, Brooks / Cole, 1979, pp. 33-37.

Tilley C. Identity, Place, Landscape and Heritage. Journal of Material Culture, 2006, no. 11, pp. 7-32. DOI 10.1177/1359183506062990

Umaña-Taylor A. J., Quintana S. M., Lee R. M., Cross W. E., Rivas-Drake D., Schwartz S. J. et al. Ethnic and Racial Identity During Adolescence and into 
Young Adulthood: An Integrated Conceptualization. Child Development, 2014, no. 85 , pp. 21-39. DOI $10.1111 /$ cdev.12196

Umaña-Taylor A., Updegraff K. Latino Adolescents' Mental Health: Exploring the Interrelations among Discrimination, Ethnic Identity, Cultural Orientation, Selfesteem, and Depressive Symptoms. Journal of Adolescence, 2007, no. 30, pp. 549567. DOI 10.1016/j.adolescence.2006.08.002

Verkuyten M. The Social Psychology of Ethnic Identity. London, Psychology Press, 2005.

Watts R.J., Flanagan C. Pushing the Envelope on Youth Civic Engagement: A Developmental and Liberation Psychology Perspective. Journal of Community Psychology, 2007, no. 35, pp. 779-792. DOI 10.1002/jcop.20178

Watts R. J., Diemer M. A., Voight A. M. Critical Consciousness: Current Status and Future Directions. New Directions for Child and Adolescent Development, 2011, no. 2011, pp. 43-57. DOI 10.1002/cd.310

Weber A., Hiers W., Flesken A. Politicized Ethnicity: A Comparative Perspective. New York, Palgrave Macmillan, 2016.

Yu M., Stifman A. R. Culture and Environment as Predictors of Alcohol Abuse / Dependence Symptoms in American Indian Youths. Addictive Behaviors, 2007, no. 32, pp. 2253-2259. DOI 10.1016/j.addbeh.2007.01.008

Zagefka H. The Concept of Ethnicity in Socio-Psychological Research: Definitional Issues. International Journal of Intercultural Relations, 2009, no. 33, pp. 228-241.

\section{References}

Abizadeh A. Ethnicity, Race, and a Possible Humanity. World Order, 2001, no. 33, pp. 23-34.

Adelabu D. H. Future Time Perspective, Hope, and Ethnic Identity among African American Adolescents. Urban Education, 2008, no. 43, pp. 347-360. DOI 10.1177/ 0042085907311806

Afanasyeva V. V. Homo Virtualis: psikhologicheskiye kharakteristiki [Homo Virtualis: Psychological Characteristics]. Izvestiya Saratovskogo universiteta. Novaya seriya. Seriya: Filosofiya. Psikhologiya. Pedagogika, 2010, vol. 10, no. 2, pp. 59-64. (in Russ.)

Barrett M. English Children's Acquisition of a European Identity. In: Breakwell G., Lyons E. (eds.). Changing European Identities: Social-Psychological Analyses of Social Change. Oxford, Butterworth-Heinemann, 1996, pp. 145-172.

Belinskaya E. P., Stefanenko T. G. Etnicheskaya sotsializatsiya podrostka [Ethnic Socialization of a Teenager]. Moscow, Voronezh, 2000. (in Russ.) 
Belokopyt A. N. Etnosotsial'nyye protsessy v usloviyakh sotsial'noy transformatsii: na primere Stavropol'skogo kraya [Ethnosocial Processes in the Context of Social Transformation: on the Example of the Stavropol Territory]. Abstract of thesis. Diss. ... Cand. Sociol. Sci. Moscow, 2004. (in Russ.)

Berger P. Priglasheniye v sotsiologiyu: gumanisticheskaya perspektiva [Invitation to Sociology: A Humanistic Perspective]. Moscow, 1996. (in Russ.)

Diemer M. A., McWhirter E. H., Ozer E. J., Rapa L. J. Advances in the Conceptualization and Measurement of Critical Consciousness. The Urban Review, 2015, no. 47, pp. 809-823. DOI 10.1007/s11256-015-0336-7

Diemer M. A., Rapa L. J. Unraveling the Complexity of Critical Consciousness, Political Efficacy, and Political Action Among Marginalized Adolescents. Child Development, 2016, no. 87, pp. 221-238. DOI 10.1111/cdev.12446

Druzhba O. V., Kairova I. A., Koshman N. V. Sotsial'nyye seti kak prostranstvo internet-sotsializatsii molodezhi [Social Networks as a Space for Internet Socialization of Youth]. KANT, 2020, no. 1 (34), pp. 143-151. (in Russ.)

Erikson E. H. Identity Youth and Crisis. New York, London, WW Norton \& Company, 1968.

Freire P. Pedagogy of the Oppressed. New York, Continuum, 2005.

Glukhov A. P. Smena lokusa etnicheskogo diskursa: sotsial'nyye seti kak "mashiny vosproizvodstva" etnichnosti [Changing the Locus of Ethnic Discourse: Social Networks as "Reproduction Machines" of Ethnicity]. Science Time, 2015, no. 10 (22), pp. 68-73. (in Russ.)

Guilamo-Ramos V. Maternal Infuence on Adolescent Selfesteem, Ethnic Pride and Intentions to Engage in Risk Behavior in Latino Youth. Prevention Science, 2009, no. 10, pp. 366-375. DOI 10.1007/s11121-009-0138-9

Heberle A. E., Rapa L. J., Farago F. Critical Consciousness in Children and Adolescents: A Systematic Review, Critical Assessment, and Recommendations for Future Research. Psychological Bulletin, 2020, no. 146, pp. 525-551. DOI 10.1037/ bul0000230.

Jemal A. Critical Consciousness: A Critique and Critical Analysis of the Literature. The Urban Review, 2017, no. 49, pp. 602-626. DOI 10.1007/s11256-017-0411-3

Kazaryan A. G. Kommunikativnyy faktor $\mathrm{v}$ etnogeneze [Communicative Factor in Ethnogenesis]. Aspirantskiy vestnik Povolzh'ya, 2018, no.7-8, pp. 25-29. (in Russ.)

Marcia J. E. The Ego Identity Status Approach to Ego Identity. In: Ego Identity. New York, Springer, 1993.

Matveyeva E. V. Sotsseti kak sredstvo formirovaniya etnicheskoy identichnosti molodezhi v dosuge [Social networks as a means of forming the ethnic identity of 
young people in their leisure]. In: Baykal'skiye vstrechi: etnichnost' v kontekste sotsial'no-kul'turnogo i ekonomicheskogo razvitiya regiona [Baikal Meetings: Ethnicity in the Context of Socio-Cultural and Economic Development of the Region]. Proceedings of the Int. Sc.-Pract. Conf. Ulan-Ude, 2016, pp. 78-83. (in Russ.)

Mead M. Kul'tura i mir detstva: Izbrannyye proizvedeniya [Culture and the World of Childhood: Selected Works]. Moscow, Nauka, 1988. (in Russ.)

Nikolayeva Zh. V., Troitskaya A. A. Diskurs ob identichnosti kak sposob osmysleniya gorodskogo prostranstva [Discourse on Identity as a Way of Understanding Urban Space]. Zhurnal frontirnykh issledovaniy, 2020, vol. 5, no. 1, pp.11-28. (in Russ.) DOI 10.24411/2500-0225-2020-10001

Persidskaya O. A. Vliyaniye etnicheskoy identichnosti na predstavleniya o mezhetnicheskoy integratsii: k postanovke problemy [The Influence of Ethnic Identity on the Idea of Interethnic Integration: to the Formulation of the Problem]. Respublica Literaria, 2020, vol. 2, no. 1, pp.95-103. (in Russ.) DOI 10.47850/RL.2021. 2.1.95-103

Phinney J. S. Ethnic Identity in Adolescents and Adults: Review of Research. Psychological Bulletin, 1997, no. 108, pp. 499-514. DOI 10.1037/0033-2909.108.3.499

Phinney J. S. Stages of Ethnic Identity Development in Minority Group Adolescents. The Journal of Early Adolescence, 1989, no. 9, pp. 34-49. DOI 10.1177/0272 431689091004

Phinney J. S., Ong A. D. Conceptualization and Measurement of Ethnic Identity: Current Status and Future Directions. Journal of Counseling Psychology, 2007, no. 54, pp. 271-281. DOI 10.1037/0022-0167.54.3.271

Pleshakov V. A. Kibersotsializatsiya kak innovatsionnyi sotsial'no-pedagogicheskii fenomen [Cyber Socialization as an Innovative Social and Pedagogical Phenomenon]. Prepodavatel' XXI vek, 2009, no. 3-1, pp. 32-39. (in Russ.)

Popkov Yu. V., Kostyuk V. G., Persidskaya O. A. Institutsionalizatsiya Novosibirskoi nauchnoi etnosotsiologicheskoi shkoly: idei, podkhody, formy deyatel'nosti [Institutionalization of the Novosibirsk Scientific Ethnosociological School: Ideas, Approaches, Forms of Activity]. Respublica Literaria, 2020, vol. 1, no. 1, pp. 103111. (in Russ.) DOI 10.47850/RL.2020.1.1.103-117

Popkov Yu. V., Tyugashev E. A. Fenomen goroda kak mezhetnicheskogo soobshchestva [The Phenomenon of the City as an Interethnic Community] Vserossiyskiy ekonomicheskiy zhurnal EKO, 2017, vol. 47, no. 10, pp.7-19. (in Russ.) DOI 10.30680/ECO0131-7652-2017-10-7-19 
Price M. Televideniye, telekommunikatsii i perekhodnyy period: pravo, obshchestvo i natsional'naya identichnost' [Television, Telecommunications and Transition: Law, Society and National Identity]. Moscow, MSU Press, 2000. (in Russ.)

Rogers L. O., Scott M. A., Way N. Racial and Gender Identity among Black Adolescent Males: An Intersectionality Perspective. Child Development, 2015, no. 86, pp. 407-424. DOI $10.1111 /$ cdev. 12303

Tajfel H., Turner J. C. An Integrative Theory of Intergroup Conflict. In: Austin W. G., Worchel S. (eds.) The social psychology of intergroup relations. Monterey, Brooks / Cole, 1979, pp. 33-37.

Tatarko A. N., Lebedeva N. M. Psikhologiya mezhetnicheskikh otnosheniy. Etnicheskaya identichnost' i strategii mezhkul'turnogo vzaimodeystviya [Psychology of Interethnic Relations. Ethnic Identity and Intercultural Strategies]. Lambert Academic Publishing, 2010. (in Russ.)

Tilley C. Identity, Place, Landscape and Heritage. Journal of Material Culture, 2006, no. 11, pp. 7-32. DOI 10.1177/1359183506062990

Umaña-Taylor A. J., Quintana S. M., Lee R. M., Cross W. E., Rivas-Drake D., Schwartz S. J. et al. Ethnic and Racial Identity During Adolescence and into Young Adulthood: An Integrated Conceptualization. Child Development, 2014, no. 85, pp. 21-39. DOI 10.1111/cdev.12196

Umaña-Taylor A., Updegraff K. Latino Adolescents' Mental Health: Exploring the Interrelations among Discrimination, Ethnic Identity, Cultural Orientation, Selfesteem, and Depressive Symptoms. Journal of Adolescence, 2007, no. 30, pp. 549567. DOI 10.1016/j.adolescence.2006.08.002

Ushakov D. V. Rol' sem'i v vosproizvodstve etnichnosti narodov Respubliki Altay [The role of the Family in the Reproduction of Ethnicity of the Peoples of the Altai Republic]. Sotsiologicheskiye issledovaniya, 2009, no. 3, pp. 101-108. (in Russ.)

Vakhshtayn V.S. Peresborka goroda: mezhdu yazykom i prostranstvom [Rebuilding the City: Between Language and Space]. Sotsiologiya vlasti, 2014, no. 2, pp. 9-38. (in Russ.)

Verkuyten M. The Social Psychology of Ethnic Identity. London, Psychology Press, 2005.

Watts R. J., Diemer M. A., Voight A. M. Critical Consciousness: Current Status and Future Directions. New Directions for Child and Adolescent Development, 2011, no. 2011, pp. 43-57. DOI 10.1002/cd.310

Watts R. J., Flanagan C. Pushing the Envelope on Youth Civic Engagement: A Developmental and Liberation Psychology Perspective. Journal of Community Psychology, 2007, no. 35, pp. 779-792. DOI 10.1002/jcop.20178 
Weber A., Hiers W., Flesken A. Politicized Ethnicity: A Comparative Perspective. New York, Palgrave Macmillan, 2016.

Yu M., Stifman A. R. Culture and Environment as Predictors of Alcohol Abuse / Dependence Symptoms in American Indian Youths. Addictive Behaviors, 2007, no. 32, pp. 2253-2259. DOI 10.1016/j.addbeh.2007.01.008

Zagefka H. The Concept of Ethnicity in Socio-Psychological Research: Definitional Issues. International Journal of Intercultural Relations, 2009, no. 33, pp. 228-241.

\section{Информация об авторах}

\section{Ольга Алексеевна Персидская}

младший научный сотрудник, Институт философии и права СО РАН

\section{Федор Сергеевич Фомкин}

младший научный сотрудник, Институт философии и права СО РАН

\section{Information about the Authors}

\section{Olga A. Persidskaya}

Junior Researcher, Institute of Philosophy and Law SB RAS

\section{Fedor S. Fomkin}

Junior Researcher, Institute of Philosophy and Law SB RAS 